\title{
Labyrinthe
}

32 | 2009 (1)

Le petit théâtre intellectuel

\section{Appendice - Réponses à quelques critiques}

\section{CpenEdition \\ 1 Journals}

Édition électronique

URL : http://journals.openedition.org/labyrinthe/3981

DOI : $10.4000 /$ labyrinthe.3981

ISSN : 1950-6031

Éditeur

Hermann

\section{Édition imprimée}

Date de publication : 19 juin 2009

Pagination : 19-22

ISBN : 978-2-7056-6885-3

\section{Référence électronique}

"Appendice - Réponses à quelques critiques », Labyrinthe [En ligne], 32 | 2009 (1), mis en ligne le 01

février 2011, consulté le 20 avril 2019. URL : http://journals.openedition.org/labyrinthe/3981 ; DOI : 10.4000/labyrinthe.3981

Propriété intellectuelle 


\section{APPENDICE Réponses à quelques critiques}

\section{Pourquoi si peu de femmes figurent-elles dans ce dossier?}

Même s'il n'était pas question de pratiquer quotas et distributions consensuelles, la question nous semble parfaitement légitime. Elle se pose à un triple niveau: celui des Caractères, celui des Portraits, celui des auteurs. Quant aux Caractères, la responsabilité incombe à la langue française, ou plus exactement au « phallogocentrisme » qui l'habite (jadis analysé par Derrida): la seule Pythie résiste à la domination masculine, et la Victime en sous-caractère. Impossible par exemple de féminiser le Témoin, difficile et périlleux de transformer l'Expert en Experte. Le problème est tout autre dans les portraits, où Sabina Guzzanti est bien seule parmi les mâles. On pourrait là encore, pas totalement à tort, renvoyer à la configuration de l'espace public où le parleur prévaudrait sur la parleuse. Nous ne sommes nous-mêmes pas convaincus car bien des femmes figuraient dans notre liste initiale (Butler, Spivak, Rice, Fouque, etc.). Pure contingence dans la constitution du dossier, où textes prévus ou promis restent souvent dans les limbes? À moins qu'il ne faille pointer du doigt le troisième niveau, et remarquer qu'il n'est pas de femme parmi les auteurs des textes. Nous laissons la question suspendue, et prenons acte des lacunes, en renvoyant à de prochains numéros l'écriture et la publication de ces « portraits manquants» (voir la liste au terme de la section « Portraits »).

Corollaire: le champ culturel couvert par vos portraits est bien restreint, pourquoi donc?

Même réponse donc, quant aux " quotas ", mais aussi quant aux regrettables lacunes. Il est certain que l'espace français est majoritaire (mais non privilégié) dans les Portraits, et modèle aussi largement notre distribution de Caractères. Ce n'est pas pour rien, en tout cas pas seulement pour signaler un ton plaisant et une certaine légèreté que nous avons qualifié ce théâtre de "petit»: c'est qu'il est incomplet et inachevé. Il ne demande qu'à être peuplé de nouveaux Portraits, et de nouveaux Caractères. 
Pourquoi Alain Badiou n'a-t-il pas droit à un portrait en bonne et due forme?

Notre préférence concernant les portraits alla très vite, nous l'avons dit, pour des figures singulières insaisissables, afin de tester les vertus heuristiques de nos Caractères. Comme bien d'autres, Alain Badiou ne satisfaisait pas pleinement à nos critères, ses interventions publiques obéissant d'après nous à une logique traditionnelle, antérieure à la configuration contemporaine que nous étudions (on trouvera des précisions sur ce point dans le texte qui lui est finalement consacré). Il n'était donc pas nécessaire d'en brosser le portrait. Cependant, plus d'un lecteur nous fit remarquer qu'il était étrange de ne pas mettre en scène un penseur qui a pris une telle importance dans le débat public ces dernières années. Comment en parler sans en parler? Une remarquable homologie nous frappa: Alain Badiou transposait à l'échelle des Portraits le problème que « l'intellectuel » nous posait au niveau de la configuration globale, et partant, de la composition des Caractères. S'il n'est pas - et pour cause - de Caractère consacré à « l'intellectuel », ce dernier est tout de même présent dans tel ou tel texte, sur un mode furtif et problématique. On adopta alors une solution analogue: faire apparaître Badiou en contrepoint d'un autre personnage du Petit Théâtre. Jacques Rancière était tout désigné, étant donné les nombreuses intersections entre leurs trajectoires personnelles et philosophiques. La publication hors-dossier - en une position d'écart significatif, donc - d'un entretien accordé par Badiou nous semble compléter très heureusement le dispositif.

Ne craignez-vous pas que vos propos ne viennent alimenter un certain " anti-intellectualisme »? Comment vous situez-vous par rapport à ceux qui proclament la « disparition des intellectuels » pour s'en féliciter ou pour le déplorer?

Non, il n'y a chez nous aucun « anti-intellectualisme ». Ce serait mal comprendre notre travail. Vouloir arrimer la notion d' « intellectuel» à une certaine forme de savoir commun, en la désubstantivant, c'est rejoindre par exemple les propositions de Jérôme Vidal et Charlotte Nordmann dans les deux tomes de La Fabrique de l'impuissance', et, avant eux,

1. Jérôme Vidal, La Fabrique de l'impuissance: tome I, La gauche, les intellectuels et le libéralisme sécuritaire, Paris, Amsterdam, 2008; Charlotte Nordmann, La Fabrique de l'impuissance: tome II, L'école entre domination et émancipation, Paris, Amsterdam, 2007. 


\section{Appendice}

celles de Jacques Rancière. Rappelons ainsi comment Rancière a pu définir sa propre position:

Je ne me considère pas comme un « intellectuel ». Je suis, d'une part, un enseignant-chercheur et un écrivain, qui s'applique à mettre en forme ses questions et ses découvertes, à l'usage de ses étudiants et de toute personne que cela intéresse. J'exerce d'autre part, comme n'importe qui ma capacité à réfléchir et à parler sur ces affaires communes que des spécialistes voudraient accaparer. La figure médiatique de l'« intellectuel » naît de la confusion de ces deux capacités bien distinctes. Cette confusion devient grave quand elle aboutit à l'auto-institution d'un corps de spécialistes de la pensée intervenante. Qui accepte de s'identifier à une telle figure le paie invariablement d'un affaiblissement de ses capacités d'observation et de raisonnement ${ }^{1}$.

Il n'est pas sans intérêt de confronter ces propos, auxquels nous acquiesçons, à ceux, nettement plus ambigus, exprimés par le même Rancière dans un article publié trois ans auparavant dans la revue Lignes, « Ce qu'"intellectuel" peut vouloir dire ${ }^{2}$ »: Jacques Rancière y défendait l'idée qu'un sens possible du substantif « intellectuel» serait « politique », dans le sens spécifique qu'il donne à ce mot. « Intellectuel » viendrait faire jouer la « tautologie égalitaire » contre la « tautologie inégalitaire ${ }^{3} »$, comme subjectivation politique, tout comme « ouvrier » et « prolétaire » avant lui. Comme l'a souligné Charlotte Nordmann ${ }^{4}$, une telle position permettait à Rancière de retrouver (un peu vite) un usage finalement très traditionnel de la notion: le terme continue de désigner « ceux qui parlent là où d'autre voix se taisent ou d'autres sujets politiques font défaut ${ }^{5}$ " . Certes, on aimerait souscrire à la proposition suivante :

Les manifestes intellectuels d'aujourd'hui, comme les manifestes ouvriers d'hier, rassemblent des individus non point selon leur occupation ou leur compétence, mais selon leurs parcours singuliers dans le monde de l'égalité

\footnotetext{
1. Réponse aux questions de Roger-Pol Droit à propos du livre de Régis Debray, Grandeur ou décadence des intellectuels français?, dans Le Monde du 15 décembre 2000.

2. Jacques Rancière, « Ce qu' "intellectuel” peut vouloir dire », Lignes $n^{\circ} 32$ « Les intellectuels : tentative de définition par eux-mêmes », Paris, Hazan, octobre 1997, pp. 116-120.

3. Ibid., p. 117.

4. Charlotte Nordmann, Bourdieu/Rancière, Paris, Amsterdam, 2006, pp. 135-137.

5. Rancière, op. cit., p. 118.
} 
des êtres parlants, selon leur expérience particulière de cette propriété générale de l'animal littéraire qui fonde l'animal politique'.

Mais il n'est pas sûr que le « sujet politique » qui se dessine ainsi ne préexiste pas encore à sa «manifestation en acte », sous la forme de ceux qui peuvent parler là ou d'autres sont contraints de se taire. En attendant, donc, mieux vaut mettre provisoirement le substantif au placard ${ }^{2}$. En reprenant les termes de Jérôme Vidal, on dira donc:

Il ne s'agit pas de proclamer, sur le mode impératif ou prophétique, la fin des intellectuels ou de professer l'une ou l'autre des variantes du relativisme postmoderne. Il s'agit de travailler activement à étendre de façon maximale les frontières de l'intellectualités.

Nous aimerions que nos Caractères soient lus dans cette perspective: dans la plupart des cas, ils ne sont ni tout noirs ni tout blancs. Aucun ne peut prétendre à une position dominante (soit se substituer à « l'intellectuel »), il était donc capital de marquer leurs limites, leurs ridicules, leurs « angles morts ». Certes, il en est qui sont croqués plus férocement que d'autres, comme le Renégat ou l'Expert: nous assumons le choix politique qu'implique tel traitement. Mais hormis ces quelques cas, nous voulons aussi mettre en évidence la puissance critique de nos personnages, leur force argumentative et leur capacité d'intervention, disponibles pour tout un chacun.

1. Lignes, art. cit., p. 120.

2. Ce que faisait Rancière, concédons-le, au début de l'article cité (ibid., pp. 116-117), en privilégiant la fonction adjectivale du terme, associée au substantif « égalité ».

3. Jérôme Vidal, op. cit., pp. 168-169. 